\title{
NOTE
}

\section{Role of Crassicauda sp. in natural mortality of pantropical spotted dolphins Stenella attenuata: a reassessment}

\author{
Juan Antonio Balbuena ${ }^{1, *}$, Andrew Simpkin ${ }^{2}$ \\ ${ }^{1}$ Cavanilles Institute of Biodiversity and Evolutionary Biology, University of Valencia, PO Box 22085, 46071 Valencia, Spain \\ ${ }^{2}$ School of Social and Community Medicine, University of Bristol, Canynge Hall, 39 Whatley Road, Clifton, Bristol BS8 2PS, UK
}

\begin{abstract}
Evaluating the effect of parasites on population size is essential for designing management and conservation plans of wild animal populations. Although knowledge in this area is scarce in cetaceans, current evidence suggests that species of the nematode genus Crassicauda may play an important regulatory role in some populations. In the present study, a semiparametric regression technique was applied to a previously published dataset to re-examine the role of Crassicauda sp. in natural mortality of pantropical spotted dolphins Stenella attenuata. The resulting model indicated parasite-induced mortality at ages between 6.5 and 9 yr and at roughly 12 yr. The maximum mortality estimates obtained could represent 2 to $4 \%$ of natural mortality in dolphins 6 to $8 \mathrm{yr}$ old. This estimate is substantially smaller than previously published values, but in contrast with previous research, our model provides clear statistical evidence for parasite-induced mortality because the bootstrapped $95 \%$ confidence intervals of the estimated mortality rates excluded the 0 value. We also evaluated, through simulations, how potential sampling biases of infected dolphins could overestimate parasite-induced mortality. Small differences in sampling selectivity between infected and uninfected animals could substantially reduce the mortality estimates. However, the simulated models also supported the notion of statistically significant mortality in juvenile dolphins. Given that dolphins older than 16 yr were poorly represented in the dataset, further research is needed to establish whether Crassicauda sp. causes meaningful mortality for population dynamics among adult individuals.
\end{abstract}

KEY WORDS: Parasite-induced mortality - Cetacea · Nematoda - Population dynamics • Semiparametric regression

Resale or republication not permitted without written consent of the publisher

\section{INTRODUCTION}

Cetacean conservation is a pressing issue as many populations worldwide face a number of serious threats, including habitat degradation, interaction with fisheries and climate change (Ross 2006, Lassalle et al. 2012, Srinivasan et al. 2012). The design and adoption of sound management and conservation plans requires evaluation of how population size may be limited by parasites and pathogens, but knowledge in this area in cetaceans is still scarce due to the cryptic nature of these animals. Strong evidence for parasite regulation of wild mammal populations has been obtained by cross-sectional research and field experiments manipulating parasite burdens with antihelminthics (Irvine 2006). The transfer of these approaches to cetaceans is severely hampered by the enormous difficulties in field sampling, the limited possibilities for experimental work and the poor knowledge of many host-parasite sys- 
tems. However, we currently have sufficient evidence to correlate parasitic infections with population dynamics (Perrin \& Powers 1980, Lambertsen 1986, 1992, Geraci \& St. Aubin 1987, Raga et al. 1997, 2009, Aznar et al. 2001).

Although many cetacean parasites (e.g. ectoparasites and gastrointestinal helminths) probably cause little damage to their hosts, others seem harmful enough as to produce substantial morbidity and mortality. These include trematodes from the cranial sinuses (Nasitrema spp.), liver flukes (Brachycladiidae), lungworms (Pseudaliidae) and tissue nematodes (Crassicaudidae) (Geraci \& Lounsbury 2001). Several species of the genus Crassicauda, in particular, may play an important regulatory role. These worms can attain a very large size (several metres in length; Gibson et al. 1998) in the host tissues and are endemic in a number of cetacean populations (Lambertsen 1992, Raga et al. 1997). Different species occur in the urogenital system, mammary glands, abdominal muscle and cranial sinuses (Dailey 1985, Geraci \& St. Aubin 1987), where they can cause extensive and profound damage to the surrounding tissues (Zucca et al. 2004, Van Bressem et al. 2006, Oliveira et al. 2011, Arbelo et al. 2013). Cranial bone lesions are of particular interest. They probably result from erosion of the carbon-rich bone fraction by glycosaminoglycan-degrading enzymes secreted by the parasite (Pascual et al. 2000). Due to their characteristic basket-like morphology, the lesions are readily attributable to Crassicauda spp. (Raga et al. 1982) and are assumed to be irreversible (Dailey \& Perrin 1973, Van Bressem et al. 2006), which provides a convenient way to trace previous infections in animals found stranded or taken as by-catch in fisheries. Using this approach, the lower incidence of residual bone lesions in older animals in some dolphin populations has been interpreted as evidence for Crassicauda spp. representing a major cause of natural mortality in some populations (Geraci \& St. Aubin 1987, Raga et al. 1997, Aznar et al. 2001).

Crassicauda spp. also deserve attention because 2 previous studies are among the rare examples in which the effect of parasites on cetacean populations has been quantified. Lambertsen (1986) estimated the mortality caused by C. boopis, a renal parasite, in fin whales Balaenoptera physalus as 4.4 to $4.9 \%$. Given that the total natural annual mortality rate in large whales is usually assumed to be between 4 and $7 \%$, infections with C. boopis would account for a substantial fraction of the total mortality of this endangered species (Lambertsen 1986). Likewise, Perrin \& Powers (1980) evaluated the potential regu- latory role of Crassicauda sp. of pantropical spotted dolphins Stenella attenuata. Their study was based on the quantification of skull lesions in dolphins killed incidentally in purse-seine tuna fisheries in the eastern tropical Pacific. The dolphins were aged based on the number of dentinal layers, total length or skull sutural closure, and the proportion of animals with lesions was determined for each age class. The authors estimated that infections with Crassicauda sp. could represent 11 to $14 \%$ of the population's natural mortality (Perrin \& Powers 1980). This study has become a paradigm of how cross-sectional data can be used to infer parasite-induced mortality in cetaceans (Dailey 1985, Geraci \& St. Aubin 1987, Raga et al. 1997, Aznar et al. 2001).

Although the exponential models used by Perrin \& Powers (1980) were a reasonable analytical option at the time of publication, enormous progress in regression methods has been made in the last 3 decades (Hastie \& Tibshirani 1990, Fan \& Gijbels 1996, Rupert et al. 2003). Current nonparametric and semiparametric regression can more efficiently tackle the lack of both normality of the error terms and nonlinearity between the dependent and independent variables of this particular dataset. Perrin \& Powers (1980) coped with the latter problem by fitting different weighted exponential models to arbitrarily delimited subsets of age-class groups (Fig. 1a), resulting in 4 different sets of estimates. In the present paper, we applied a semiparametric regression technique to Perrin \& Powers' (1980) data in order to optimize and obtain a single model describing the variation of skull-lesion prevalence with dolphin age. Our objective was to produce a more appropriate model for the data and thus more reliable estimates of parasiteinduced mortality. Consequently, we expect to improve inference about the effect of parasitism by Crassicauda sp. at the population level. In addition, given that a central assumption for the analyses is that nematode infections do not increase the likelihood of dolphins being killed in the fishery (Perrin \& Powers 1980), we also explored the effect on mortality estimates of potential selective sampling in favour of infected dolphins.

\section{METHODS}

The present study is based on the data reported in Table 1 of Perrin \& Powers (1980) showing the prevalence of skull lesions produced by Crassicauda sp. in 704 spotted dolphins caught incidentally in tuna fisheries. Our dataset was organized in 704 rows (indi- 


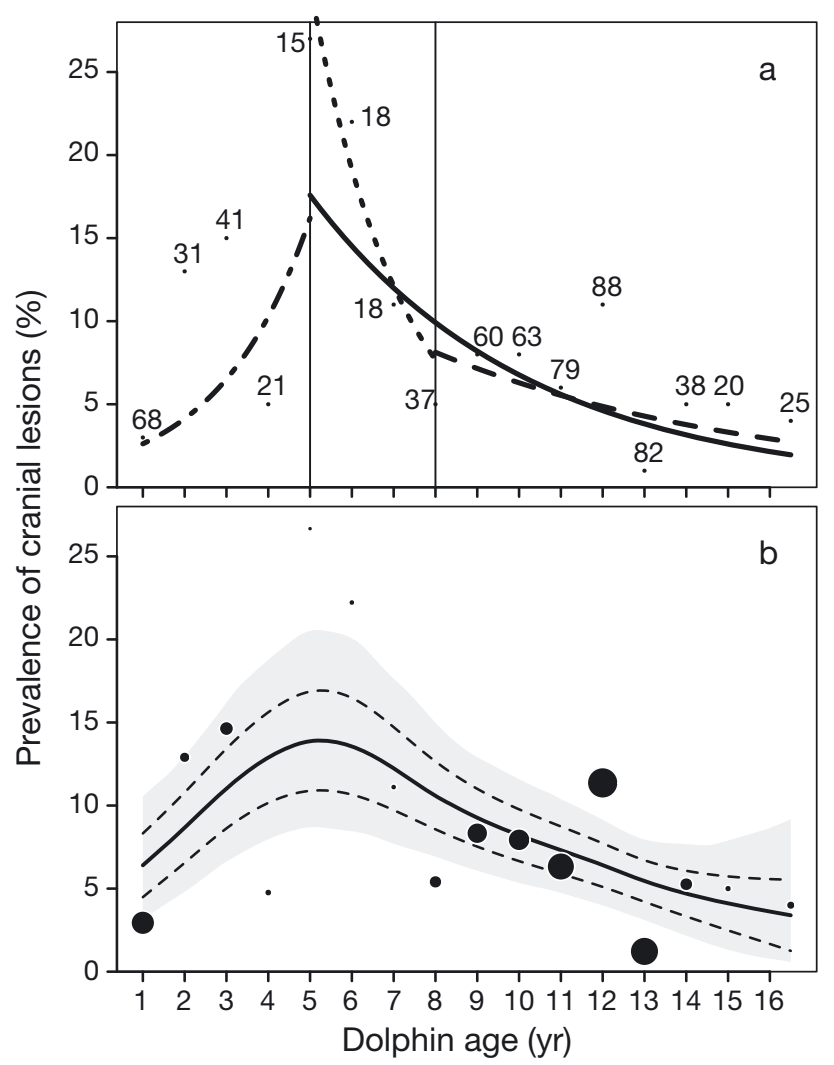

Fig. 1. Stenella attenuata. Models describing variation in the prevalence of skull lesions produced by Crassicauda sp. in an age-stratified sample of 704 pantrotical spotted dolphins incidentally killed in tuna fisheries. (a) Perrin \& Powers' (1980) models. Weighted exponential regressions were fitted to 4 different age intervals: 1-5 yr (dot-dashed line), 5-8 yr (dotted line), 5-16+ yr (continuous line) and 8-16+ (dashed line). Points represent the observed prevalence for each age and numbers indicate sample size. (b) Present study. A cubic spline with 4 effective degrees of freedom fitted with generalized additive models for location, scale and shape (continuous line). Bootstrapped standard error bands (dashed lines) and 95\% confidence intervals (grey area) are displayed. Data points are scaled to the sample sizes indicated in (a)

vidual dolphins) with 2 column variables: a binary response variable, denoting for each individual dolphin the presence (1) or absence (0) of skull lesions, and dolphin age as an independent variable. Animals $(\mathrm{n}=25)$ clustered in the $16-19$ yr age class in Perrin \& Powers (1980) were arbitrarily assigned to age 16.5. We used generalized additive models for location, scale and shape (GAMLSS) (Rigby \& Stasinopoulos 2005) to estimate a function $\hat{f}(a)$ describing the variation of prevalence of skull lesions across dolphin age (a). Our choice of this regression technique is justified for 2 main reasons. First, model optimization and selection are facilitated by the large variety of distributions for the response variable that can be tested and by the range of additive terms allowed. Second, powerful and reliable algorithms are used to fit the models (Rigby \& Stasinopoulos 2005). The analyses were carried out with the gamlss package (Stasinopoulos \& Rigby 2007) in R 3.0.1 (R Core Team 2013).

We evaluated different candidate models allowing 4 different binomial-type distributions (binomial, beta-binomial, 0 -inflated binomial and 0-inflated beta-binomial) for the response variable, tested over a range of functions: linear, exponential, cubic soothing splines (Reinsch 1967) and penalized B-splines (Eilers \& Marx 1996). The models were fitted using the Rigby-Stasinopoulos algorithm (Rigby \& Stasinopoulos 2005) and were compared to select the best model for the data based on differences in Akaike's Information Criterion (AIC) (Burnham \& Anderson 2002). We eventually checked the adequacy of the chosen model to the data by inspection of the detrended normal Q-Q plots of the residuals (worm plots) (van Buuren \& Fredriks 2001).

In order to estimate the rates of change with age of nematode infections, we computed the first derivative of the model function $\hat{f}^{\prime}(a)$ by numerical methods in $\mathrm{R}$ (see the Supplement at www.int-res.com/articles/ suppl/d108p083_supp.pdf). Then the net rate of change in lesion prevalence with respect to age $\hat{z}(a)$ was estimated as $\hat{z}(a)=\hat{f}(a) \times \hat{f}^{\prime}(a)$. This function is analogous to the net exponential rate of change $z$ used by Perrin \& Powers (1980), which represents the turnover between infection and mortality rates $(r$ and $m$, respectively), i.e. $z=r-m$. To establish the accuracy of our models, standard errors (SEs) and non-parametric 95\% confidence intervals (CIs) for $\hat{f}(a)$ and $\hat{z}(a)$ were computed based on 1000 bootstrap replicates of the dataset, where each function was evaluated on a fixed grid of 100 points equally spaced along the full range of age classes. Values are reported herein as $\hat{z}(a) \pm \mathrm{SE}$, followed by the $95 \% \mathrm{CI}$ in parentheses.

If infected dolphins were more likely to be incidentally killed in the purse-seine fishery than uninfected ones, mortality rates would be overestimated. For this reason, we heuristically assessed the potential effect on our mortality estimates of differences in sampling selectivity between infected and uninfected dolphins. Weighted GAMLSS regressions were fitted to the data assuming capture probabilities for infected animals of 1.25, 1.5, 1.75 and 2.0 times higher than those of uninfected ones. New $\hat{z}(a)$, SE and CI values were then computed as above and compared to those obtained with the original data. 


\section{RESULTS}

Models assuming a binomial distribution for the response variable fitted the data better than the other candidate distributions (AIC values are given in the Supplement). The best model (Fig. 1b) was defined by a cubic smoothing spline with 4 effective degrees of freedom. In this model, age was a significant predictor of skull-lesion prevalence (likelihood ratio test, $D=9.94, \mathrm{p}=0.019$ ). The model showed a statistically significant increase (CIs of $\hat{z}(a) \operatorname{did}$ not include 0) in lesion prevalence in the younger animals (ages between 1 and $3.5 \mathrm{yr}$ ), with the maximum net increase occurring at ages between 2.5 and $3.0 \mathrm{yr}: 0.24 \pm 0.14 \%(0.05-0.60 \%$; Fig. 2). Prevalence decreased in dolphins $\geq 5$ yr of age (Fig. 1b). This reduction was statistically significant from age 6.5 to $9 \mathrm{yr}$ and at roughly $12 \mathrm{yr}$ (Fig. 2), and the minimum net change in prevalence was reached at ca. $7 \mathrm{yr}$ of age: $-0.19 \pm 0.14 \%(-0.60$ to $-0.017 \%$ ) (Fig. 2). A similar pattern was observed when sampling biases in favour of infected dolphins were assumed, with maximum and minimum net increases also occurring at about 3 and 7 yr of age, respectively, but the estimated absolute net rates of prevalence change were smaller than in the original model (see the Supplement). In fact, the relationship between the absolute values of the maximum and minimum net increases, and hypothetical sampling biases in favour of infected dolphins agreed well with power laws with scaling exponents $<-1.7$ in both cases (Fig. 3).

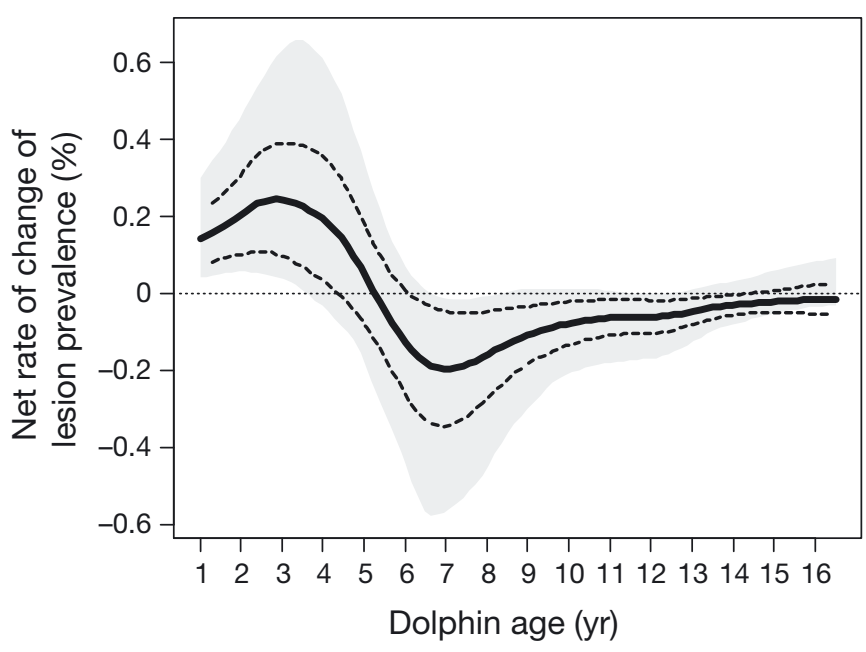

Fig. 2. Stenella attenuata. Variation of net change rate in skull lesion prevalence across dolphin age (continuous line) with bootstrapped standard error bands (dashed lines) and $95 \%$ confidence intervals (grey area)

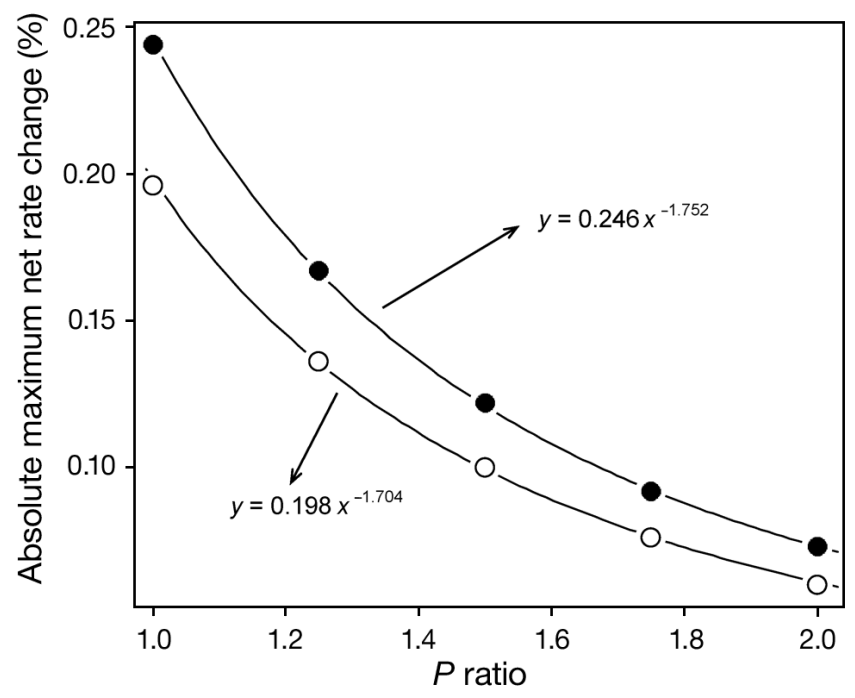

Fig. 3. Stenella attenuata. Effect of potential sampling biases in favour of infected dolphins on the maximum at ca. $3 \mathrm{yr}$ $(-)$ and minimum at ca. $7 \mathrm{yr}(\mathrm{O})$ net range of change in skull lesion prevalence (Fig. 2). Absolute values of the maxima and minima are displayed assuming different ratios of infected to uninfected dolphins in the probability $(P)$ of being incidentally killed in the tuna fishery. The data were fitted well by 2 power laws

\section{DISCUSSION}

Our model describes the variation in prevalence of cranial bone lesions produced by Crassicauda sp. in 704 spotted dolphins caught incidentally in tuna fisheries (Perrin \& Powers 1980). A key assumption to accept that the significant reduction in prevalence at ages between 6.5 and 9 yr indicates mortality caused by Crassicauda sp. in the studied population is that bone lesions do not resolve with age. Otherwise, the pattern observed could also be accounted for by a decrease of infections without host mortality in that age period. However, convincing evidence for the irreversibility of these lesions has been provided by Dailey \& Perrin (1973). These authors surveyed 126 of the 704 skulls of the present dataset (Perrin \& Powers 1980) for Crassicauda lesions and found that the most severely damaged skulls corresponded to calves. The damage was extensive and, if repaired, traces would still be apparent in the form of bone calluses, depression or altered shape of bone elements. After careful examination of skulls in older individuals, no such signs were observed, which led the authors to conclude that lesions were certainly irreversible (Dailey \& Perrin 1973). A plausible mechanism to account for this finding is that the lesions consist of bone excavations involving destruction of 
periosteum, thereby disrupting normal bone repair (Zhang et al. 2008).

The completion of physiological development and attainment of independence in delphinids occurs at about 7 yr of age (Noren \& Edwards 2007). Cranial infections with Crassicauda spp. lead to a very destructive and exacerbated inflammatory reaction (Zucca et al. 2004), which can additionally affect echolocation (Dhermain et al. 2002) or facilitate bacterial and viral infections (Pascual et al. 2000). Thus these nematode infections could impact directly or indirectly on development in the early life of dolphins leading to increased mortality at this life stage.

In animals $\leq 5 \mathrm{yr}$ old, Perrin \& Powers (1980) reported a $53.9 \%$ yearly rate of increase in lesions. Given that the prevalence at age 5 was $15.4 \%$, this yields a net infection rate of $8.3 \%$, which is markedly higher than our maximum estimate $(0.24 \%)$ within the same age class. Likewise, the maximum net reduction in prevalence reported herein $(\approx 0.2 \%$ at age 7$)$ is substantially smaller than the net exponential rates given by Perrin \& Powers (1980). The authors reported 3 different values: $1.1 \%$ for dolphins $\geq 8 \mathrm{yr}$ old, $2.6 \%$ for dolphins $\geq 5$ yr of age and up to $10.6 \%$ for those in the 5-7 yr interval. However, all associated SEs were larger than the estimates and, more importantly, the SE intervals were truncated at 0 . Therefore, it could not be established with enough confidence that the true net rates are non-0. By contrast, our model provided clear statistical evidence for reduction in prevalence, and hence mortality, at specific ages because the narrower confidence bands excluded the 0 value. Probably these large discrepancies in estimates and the large SEs in Perrin \& Powers (1980) result from fitting exponential models to different subsets of data that probably lead to overfitting to the points included in each partition.

Without additional information, it is impossible to partition $\hat{z}(a)$ into its $r$ and $m$ components. Perrin \& Powers (1980) assumed that past a given age at which there is a peak of prevalence of skull lesions, no significant new lesions occur. Accordingly, after that age, $z \approx m$ and $\hat{z}(a)$ could be taken as a proxy for mortality-rate estimates at age $a$. Given that the natural mortality rate of eastern tropical spotted dolphins has been estimated to be $9.8 \%$ (Perrin \& Hohn 1994), nematode-induced mortality would represent up to $2 \%$ of the natural mortality at least in animals between 6 and $8 \mathrm{yr}$ old. The assumption of little or no new infections in older dolphins is based on evidence indicating the presence of eggs or larvae in milk and urine in lactating females (Dailey 1985, 2001). Accordingly, calves would become infected when suck- ling or by ingestion of larvae released in the mother's urine (Lambertsen 1986). In addition, worms have been reported in a newborn fin whale, which suggests a transplacental route of transmission for Crassicauda spp. (Lambertsen 1992). Although these proposed transmission mechanisms might explain the apparent increase in lesion prevalence during the first years of life (Fig. 2), they might not apply to species living in the cranial sinuses. In addition, these observations are in conflict with the obvious thickshelled eggs of Crassicauda spp. and the systematic position of Crassicaudidae within the habronematoids, in which it has been consistently shown that development to the infective larval stage takes place in arthropod intermediate hosts (Anderson 2000, Moravec 2007). Moreover, the data were best fitted by a binomial (as opposed to beta-binomial) distribution, indicating that there is no statistical evidence to assume different probabilities of infection among individuals. Thus, the hypothesis of significant infections in juvenile and adult dolphins deserves consideration. In such a case, $\hat{z}(a)$ would underestimate the true mortality. However, if we assume that the detrimental effect of Crassicauda sp. occurs sometime after infection, the maximum net increase of prevalence observed in calves might be close to $r$. Then our maximum mortality would become $0.24+0.19=$ $0.43 \%$ and thus nematode infections would account for ca. $4 \%$ of the natural mortality rate in dolphins between 6 and 8 yr old. Additional mortality could also result from infections with Crassicauda spp. not involving bone damage, but this effect is impossible to evaluate with the present dataset.

Our study also provides scaling factors affording to quantify how biases in favour of infected animals could overestimate parasite-induced mortality. We show that even for small differences in capture probability between infected and uninfected animals, the mortality estimates can be substantially reduced (Fig. 3). However, it is important to notice that the general model dynamics were very similar in the simulated regression models: Prevalence increases during the first years of age, and parasite-induced mortality mostly affects juvenile dolphins.

Our models did not provide sufficient statistical evidence for substantial mortality in older dolphins. However, not all age classes were adequately represented in the database. Spotted dolphins have a life expectancy of over $40 \mathrm{yr}$ (Perrin et al. 1987) and sexual maturity is attained at 9 to $11 \mathrm{yr}$ in females and at 12 to $15 \mathrm{yr}$ in males (Perrin 2001, 2009). Thus, most animals analysed herein were either calves, juveniles or subadults. Therefore, models including adult dol- 
phins would help clarify the role of parasite-induced mortality among the older animals.

It is clear that much more research is needed to exactly determine the effect of Crassicauda sp. on cetacean populations. The evidence brought forward herein concerns parasite-induced mortality, but macro-parasites in vertebrates can also decrease growth and fecundity (Irvine 2006). Although these effects are more subtle and more difficult to evaluate in wild mammals, the role played by Crassicauda spp. deserves further investigations. In addition, elucidating the mode of transmission of these nematodes would tremendously advance our understanding of the host-parasite dynamics. This aspect could be investigated using molecular approaches similar to those used with marine-mammal lungworms (Lehnert et al. 2010). In any case, we indicate here that although perhaps not as dramatic as suggested by Perrin \& Powers (1980), the effect of Crassicauda infections in spotted dolphins seems to be important, and this factor should be explicitly addressed in future population studies of small cetaceans. We strongly recommend systematically recording the presence of Crassicauda spp. in the cranial sinuses in all advanced programmes of cetacean research and deposition of relevant skeletal material in reference collections. In the long run, this will allow obtaining better insight into the impact of this parasite on dolphin populations worldwide.

Acknowledgements. We are grateful to M. Domingo, Autonomous University of Barcelona, for providing valuable insight into the nature of Crassicauda-induced bone lesions. This study was funded by the Generalitat Valenciana (Prometeo Grant 2011-040).

\section{LITERATURE CITED}

Anderson RC (2000) Nematode parasites of vertebrates: their development and transmission, 2nd edn. CABI Publishing, Wallingford

Arbelo M, Espinosa de los Monteros A, Herráez P, Andrada $M$ and others (2013) Pathology and causes of death of stranded cetaceans in the Canary Islands (1999-2005). Dis Aquat Org 103:87-99

Aznar FJ, Balbuena JA, Fernández M, Raga JA (2001) Living together: the parasites of marine mammals. In: Evans PGH, Raga JA (eds) Marine mammals, biology and conservation. Kluwer Academic/Plenum Publishers, New York, NY, p 385-423

Burnham KP, Anderson DR (2002) Model selection and multimodel inference: a practical information-theoretic approach, 2nd edn. Springer-Verlag, New York, NY

Dailey MD (1985) Diseases of Mammalia: Cetacea. In: Kinne $\mathrm{O}$ (ed) Diseases of marine animals, Vol IV, Part 2. Biologische Anstalt Helgoland, Hamburg, p 805-847
Dailey MD (2001) Parasitic diseases. In: Dierauf LA, Gulland FMD (eds) Marine mammal medicine, 2nd edn. CRC Press, Boca Raton, FL, p 357-379

Dailey MD, Perrin WF (1973) Helminth parasites of porpoises of the genus Stenella in the eastern Tropical Pacific, with the description of two new species: Mastigotrema stenellae gen. et sp. n. (Nematoda: Spiruroidea) and Zalophotrema pacificum sp. n. (Trematoda: Digenea). Fish Bull 71:455-471

Dhermain F, Soulier L, Bompar JM (2002) Natural mortality factors affecting cetaceans in the Mediterranean Sea. In: Notarbartolo di Sciara G (ed) Cetaceans of the Mediterranean and Black Seas: state of knowledge and conservation strategies. ACCOBAMS Secretariat, Monaco

Eilers PHC, Marx BD (1996) Flexible smoothing with B-splines and penalties. Stat Sci 11:89-102

Fan J, Gijbels I (1996) Local polynomial modelling and its applications. Chapman and Hall, London

Geraci JR, Lounsbury VJ (2001) Marine mammal health: holding the balance in an ever-changing sea. In: Evans PGH, Raga JA (eds) Marine mammals, biology and conservation. Kluwer Academic/Plenum Publishers, New York, NY, p 365-383

Geraci JR, St. Aubin DJ (1987) Effects of parasites on marine mammals. Int J Parasitol 17:407-414

> Gibson DI, Harris EA, Bray RA, Jepson PD, Kuiken T, Baker JR, Simpson VR (1998) A survey of the helminth parasites of cetaceans stranded on the coast of England and Wales during the period 1990-1994. J Zool (Lond) 244: 563-574

Hastie TJ, Tibshirani RJ (1990) Generalized additive models. Chapman and Hall, London

Irvine RJ (2006) Parasites and the dynamics of wild mammal populations. Anim Sci 82:775-781

Lambertsen RH (1986) Disease of the common fin whale (Balaenoptera physalus) - crassicaudiosis of the urinary system. J Mammal 67:353-366

Lambertsen RH (1992) Crassicaudosis: a parasitic disease threatening the health and population recovery of large baleen whales. Rev Sci Tech Off Int Epizoot 11: 1131-1141

> Lassalle G, Gascuel D, Le Loc'h F, Lobry J and others (2012) An ecosystem approach for the assessment of fisheries impacts on marine top predators: the Bay of Biscay case study. ICES J Mar Sci 69:925-938

> Lehnert K, von Samson-Himmelstjerna G, Schaudien D, Bleidorn C, Wohlsein P, Siebert U (2010) Transmission of lungworms of harbour porpoises and harbour seals: Molecular tools determine potential vertebrate intermediate hosts. Int J Parasitol 40:845-853

Moravec F (2007) Some aspects of the taxonomy and biology of adult spirurine nematodes parasitic in fishes: a review. Folia Parasitol 54:239-257

> Noren SR, Edwards EF (2007) Physiological and behavioral development in delphinid calves: implications for calf separation and mortality due to tuna purse-seine sets. Mar Mamm Sci 23:15-29

- Oliveira JB, Morales JA, González-Barrientos RC, Hernández-Gamboa J, Hernández-Mora G (2011) Parasites of cetaceans stranded on the Pacific coast of Costa Rica. Vet Parasitol 182:319-328

Pascual S, Abollo E, López A (2000) Elemental analysis of cetacean skull lesions associated with nematode infections. Dis Aquat Org 42:71-75 
Perrin WF (2001) Stenella attenuata. Mamm Species 683:1-8 Perrin WF (2009) Pantropical spotted dolphin. In: Perrin WF, Würsig B, Thewissen JG (eds) Encyclopedia of marine mammals, 2nd edn. Academic Press, Burlington, MA, p 819-821

Perrin WF, Hohn AA (1994) Pantropical spotted dolphin Stenella attenuata. In: Ridgway $\mathrm{SH}$, Harrison R (eds) Handbook of marine mammals, Vol 5. The first book of dolphins. Academic Press, London, p 71-98

Perrin WF, Powers JE (1980) Role of a nematode in natural mortality of spotted dolphins. J Wildl Manag 44:960-963

Perrin WF, Mitchell ED, Mead JG, Caldwell DK, Caldwell MC, Vanbree PJH, Dawbin WH (1987) Revision of the spotted dolphins, Stenella spp. Mar Mamm Sci 3:99-170

R Core Team (2013) R: a language and environment for statistical computing. Available at www.R-project.org (accessed 17 June 2013)

Raga JA, Casinos A, Filella S, Raduán MA (1982) Notes on cetaceans of the Iberian coasts. V. Crassicauda grampicola Johnston \& Mawson, 1941, (Nematoda) cause of injuries in the pterygoids of some specimens of Grampus griseus. Säugetierkd Mitt 30:315-318

Raga JA, Balbuena JA, Aznar J, Fernández M (1997) The impact of parasites on marine mammals: a review. Parassitologia 39:293-296

Raga JA, Fernández M, Balbuena JA, Aznar FJ (2009) Parasites. In: Perrin WF, Würsig B, Thewissen JG (eds) Encyclopedia of marine mammals, 2nd edn. Academic Press, Burlington, MA, p 821-830

Reinsch CH (1967) Smoothing by spline functions. Numer Math 10:177-183

Editorial responsibility: Michael Moore, Woods Hole, Massachusetts, USA
Rigby RA, Stasinopoulos DM (2005) Generalized additive models for location, scale and shape. J R Stat Soc Ser C Appl Stat 54:507-544

Ross GJB (2006) Review of the conservation status of Australia's smaller whales and dolphins. Report to the Australian Department of the Environment and Heritage, Canberra

Rupert D, Wand MP, Carroll RJ (2003) Semiparametric regression. Cambridge University Press, Cambridge, UK

Srinivasan M, Pearson HC, Vaughn-Hirshorn RL, Würsig B, Murtugudde R (2012) Using climate downscaling to hypothesise impacts on apex predator marine ecosystem dynamics. NZ J Mar Freshw Res 46:575-584

Stasinopoulos DM, Rigby RA (2007) Generalized additive models for location scale and shape (GAMLSS) in R. J Stat Softw 23:1-46

> Van Bressem MF, Van Waerebeek K, Montes D, Kennedy $S$ and others (2006) Diseases, lesions and malformations in the long-beaked common dolphin Delphinus capensis from the Southeast Pacific. Dis Aquat Org 68: 149-165

> van Buuren S, Fredriks M (2001) Worm plot: a simple diagnostic device for modelling growth reference curves. Stat Med 20:1259-1277

Zhang X, Awad HA, O'Keefe RJ, Guldberg RE, Schwarz EM (2008) Engineering periosteum for structural bone graft healing. Clin Orthop Relat Res 466:1777-1787

Zucca P, Di Guardo G, Pozzi-Mucelli R, Scaravelli D, Francese $M$ (2004) Use of computer tomography for imaging of Crassicauda grampicola in a Risso's dolphin (Grampus griseus). J Zoo Wildl Med 35:391-394

Submitted: June 26, 2013; Accepted: November 2, 2013

Proofs received from author(s): January 9, 2014 